\title{
MORFOLOGIA URBANA E CORREDORES DE VENTILAÇÃO COMO SUBSÍDIO À RESILIÊNCIA URBANA
}

\author{
URBAN MORPHOLOGY AND VENTILATION CORRIDORS AS A \\ SUBSIDY TO URBAN RESILIENCE
}

\author{
Rafael Gonçalves Santos \\ Doutorando em Geografia e Investigador - Centro de Estudos Geográficos, CEG / Instituto de \\ Geografia e Ordenamento do Território da Universidade de Lisboa IGOT-ULisboa. \\ E-mail: rafaelgoncalves@campus.ul.pt \\ Alessandra Rodrigues Prata-Shimomura \\ Arquiteta, Profa. Dra. em Tecnologia da Arquitetura pela Faculdade de Arquitetura e \\ Urbanismo da Universidade de São Paulo, São Paulo - SP. \\ E-mail: arprata.shimo@gmail.com \\ Ezequiel Correia \\ Professor e Investigador - Centro de Estudos Geográficos, CEG / Instituto de Geografia e \\ Ordenamento do Território da Universidade de Lisboa IGOT-ULisboa. \\ E-mail: ezequielc@campus.ul.pt \\ MARia de Assunção Ribeiro Franco \\ Professora Titular do Depto. De Projeto pela Faculdade de Arquitetura e Urbanismo da \\ Universidade de São Paulo, São Paulo - SP. /FAUUSP \\ E-mail: mariafranco@usp.br \\ AnTónio SARAIVA Lopes \\ Professor e Investigador - Centro de Estudos Geográficos, CEG / Instituto de Geografia e \\ Ordenamento do Território da Universidade de Lisboa IGOT-ULisboa. \\ E-mail:antonio.lopes@campus.ul.pt
}

\begin{abstract}
RESUMO
Este artigo apresenta a análise de corredores de ventilação para um trecho da cidade de São Paulo. Este trecho é parte integrante do projeto de Infraestrutura Verde que contempla quatro parques da cidade de São Paulo: Parque Estadual da Cantareira, Parque Dr. Fernando Costa (Água Branca), Parque do Ibirapuera, e Parque Tenente Siqueira Campos (Trianon); formando um retângulo com configurações urbanas diferenciadas no eixo norte-sul. Este eixo percorre áreas da cidade ao longo de avenidas importantes, que interligam os quatro parques, a qual recebeu o nome de "Trilha Norte-Sul". O objetivo, aqui, é a elaboração de cartografias de classificação morfológica
\end{abstract}


utilizando variáveis que descrevem a morfologia urbana. É apresentado, também, um método simplificado de análise e mapeamento dos corredores de ventilação, cujos resultados poderão servir de insumo tanto para orientações climáticas ao planejamento urbano como para intervenções urbanísticas.

Palavras-chave: Morfologia Urbana; Rugosidade; Porosidade; Fator H/W; Corredores de Ventilação.

\section{ABSTRACT}

This article presents an analysis of ventilation corridors for a stretch of São Paulo City. Such a stretch is part of the Green Infrastructure Project that includes four parks: Cantareira State Park, Dr. Fernando Costa Park (Água Branca), Ibirapuera Park and Tenente Siqueira Campos Park (Trianon), which form a rectangle with differentiated urban configurations on the north-south axis, that crosses areas of the city along important avenues interconnecting the four parks, which is named "North-South Trail". The target is to draw up cartographies of morphological classification using variables that describe the urban morphology. It is also presented a simplified method of analysis and mapping of ventilation corridors, which results may serve as a guideline for both climatic orientations and urban planning interventions.

Keywords: Urban Morphology; Roughness; Porosity; HW Factor; Ventilation Corridors.

\section{INTRODUÇÃO}

O espaço urbano pode ser compreendido como um sistema resultante da integração de três subsistemas: sistemas de espaços com construções; sistemas de espaços de integração viária e sistemas de espaços livres de construção (CAVALHEIRO e DEL PICCHIA, 1992). O sistema espaço urbano, apresenta respostas diferentes às modificações geográficas introduzidas pelo homem, dado as especificidades de cada escala do clima urbano (ALCOFORADO et al., 2000). A aglomeração de calor, sobretudo, o efeito das llhas de Calor Urbano - ICU é o principal resultado dessas modificações (ALCOFORADO et al., 2005; LOMBARDO et al., 2012).

Nos diferentes sistemas de espaços urbanos a componente térmica é influenciada pelas condições de penetração e absorção da radiação solar (albedo, capacidade térmica, emissividade) (PARLOW, 1998; SCHERER et al., 1999), pela presença da vegetação (ANDRADE, 2005), por alterações no uso e cobertura da terra, pelas propriedades dos 
materiais utilizados e por modificações da circulação do ar (LOPES, 2009).

A morfologia dos espaços urbanos interfere nos ventos locais, enquanto os materiais de construção alteram o balanço energético (OKE, 1987). No sistema espaço urbano, o efeito de circulação do ar representa uma componente essencial para atenuar as aglomerações de calor, com potencial para arrefecer a atmosfera, dificultar a formação da ICU (OKE, 1995; LOPES, 2003) e modificar sua estrutura espacial (RATTI et al., 2006). O efeito da circulação do ar apresenta, ainda, consequências no conforto térmico e mecânico (LOPES et al., 2011), além de atuar na dispersão de poluentes, melhorando a qualidade do ar (OKE, 1989).

A morfologia urbana e sobretudo o efeito da urbanização estão ainda associados a redução da fração de céu visível (OKE, 1987). A verticalização e o adensamento dos espaços construídos, dificulta a dispersão de partículas no ar, resultando na diminuição do arejamento das cidades (ALCOFORADO et al., 2005).

As cidades representam as mais ásperas superfícies subjacentes sob a camada limite atmosférica, onde os ventos regionais são constantemente alterados em velocidade $e$ direção (LOPES, 2003), o que torna o fluxo de ar um elemento complexo de ser analisado (GRIMMOND e OKE, 1999). Nesse sentido, a velocidade e direção do fluxo de ar depende da rugosidade dos elementos presentes na superfície. O conhecimento exato das características aerodinâmicas das cidades é importante para descrever, modelar e prever o comportamento da ventilação em todas as escalas.

O progressivo aumento da rugosidade e redução da fração de céu vísivel nas cidades, tem resultado na diminuição da velocidade do vento na ordem dos 20 a $30 \%$ e um aumento de 50 a 100\% nas turbulências, com elevações em decorrência das características da geometria urbana e a topografia do terreno (FARIÑA, 1998; PRATA SHIMOMURA et al., 2009; LOPES et al., 2011).

A presença do extrato arbóreo em ambientes urbanos, também, necessita ser planejada. A vegetação, ainda que apresente maior porosidade que os espaços construídos, pode modificar a velocidade e fluxo dos ventos, atuando no incremento da rugosidade em áreas de possíveis corredores de ventilação natural. O impacto da vegetação urbana na ventilação está associado ao incremento das condições de estabilidade atmosférica (dificultando a dispersão de poluentes) com reflexos negativos na qualidade do ar, na temperatura local e nas condições de conforto térmico, além de aumentar o risco de quedas em condições de vento forte (NG e CHAU, 2012; GROMKE e RUCK, 2012; VOS et al., 2013). 
As áreas com baixa rugosidade, apresentam condições favoráveis para os corredores de ventilação urbana. Nesse sentido, o mapeamento e planejamento destes espaços, apresenta potencialidades na ventilação urbana, nas condições de conforto térmico, na dispersão de poluentes e dispersão de calor.

Este estudo propõe uma abordagem baseada em métodos morfométricos para calcular as propriedades aerodinâmicas em um trecho da cidade de São Paulo. A inexistência de estudos anteriores relacionados à espacialização de diferentes indicadores morfológicos leva-nos a propor a caracterização morfológica, para fins climáticos, com base em indicadores presentes no sistema de espaços construídos em um banco de dados 3D da cidade de São Paulo. Por fim, apresenta-se uma análise e mapeamento dos corredores de ventilação em sistemas de espaços de integração viária e sistemas de espaços livres de construção, cujos resultados poderão servir de insumos tanto para orientações climáticas ao planejamento urbano como para intervenções urbanísticas.

\section{CARACTERIZAÇÃO MORFOLÓGICA DOS ÍNDICES DE RUGOSIDADE, POROSIDADE, FATOR H/W E CORREDORES DE VENTILAÇÃO}

A área de estudo compreende um eixo que percorre áreas da cidade ao longo de avenidas importantes, que interligam quatro importantes parques, intersectando 25 subprefeituras da cidade de São Paulo, a qual recebeu o nome de "Trilha Norte-Sul". A área de estudo é parte integrante do projeto de Infraestrutura Verde ${ }^{1}$ que contempla os parques (áreas verdes "ancora"): Parque Estadual da Cantareira, Parque Dr. Fernando Costa (Água Branca), Parque do Ibirapuera, e Parque Tenente Siqueira Campos (Trianon); que tem como objetivo verificar em que medidas os parques urbanos e suas bordas interligados a outras áreas verdes, podem tornar-se fatores de resiliência e adaptação à cidade de São Paulo.

Para uma análise destes locais, foram definidas 2 faixas de transecto de Infraestrutura verde propositivas de "Cenários Ambientais", denominadas "trilhas Norte-Sul 1 e 2"; formando um retângulo com configurações urbanas diferenciadas. Estas trilhas percorrem de norte a sul o Município de São Paulo, ao longo de avenidas importantes da cidade, a maioria ocupando fundos de vales, contendo rios canalizados, ou ocultos e tubulados,

\footnotetext{
1 Projeto de Pesquisa Auxílio Regular FAPESP de n 2015/10597-0, intitulado - "Infraestrutura Verde para a Resiliência Urbana às Mudanças Climáticas da Cidade de São Paulo, tendo a Profa Dra Maria de Assunção Ribeiro Franco como Pesquisador Responsável.
} 
e canteiros centrais geralmente arborizados. O retângulo de estudo constitui-se, assim, numa área piloto de experimentação a qual foi dividida transversalmente por 5 linhas de transepto com subdivisões em 6 zonas de compartimentação ambiental, seguindo lógicas de geomorfologia, morfologia urbana, mobilidade e bem estar social, Figura 1.

Mapa Temático com Cenários Ambientais - TRANSECTOS E TRANSEPTOS
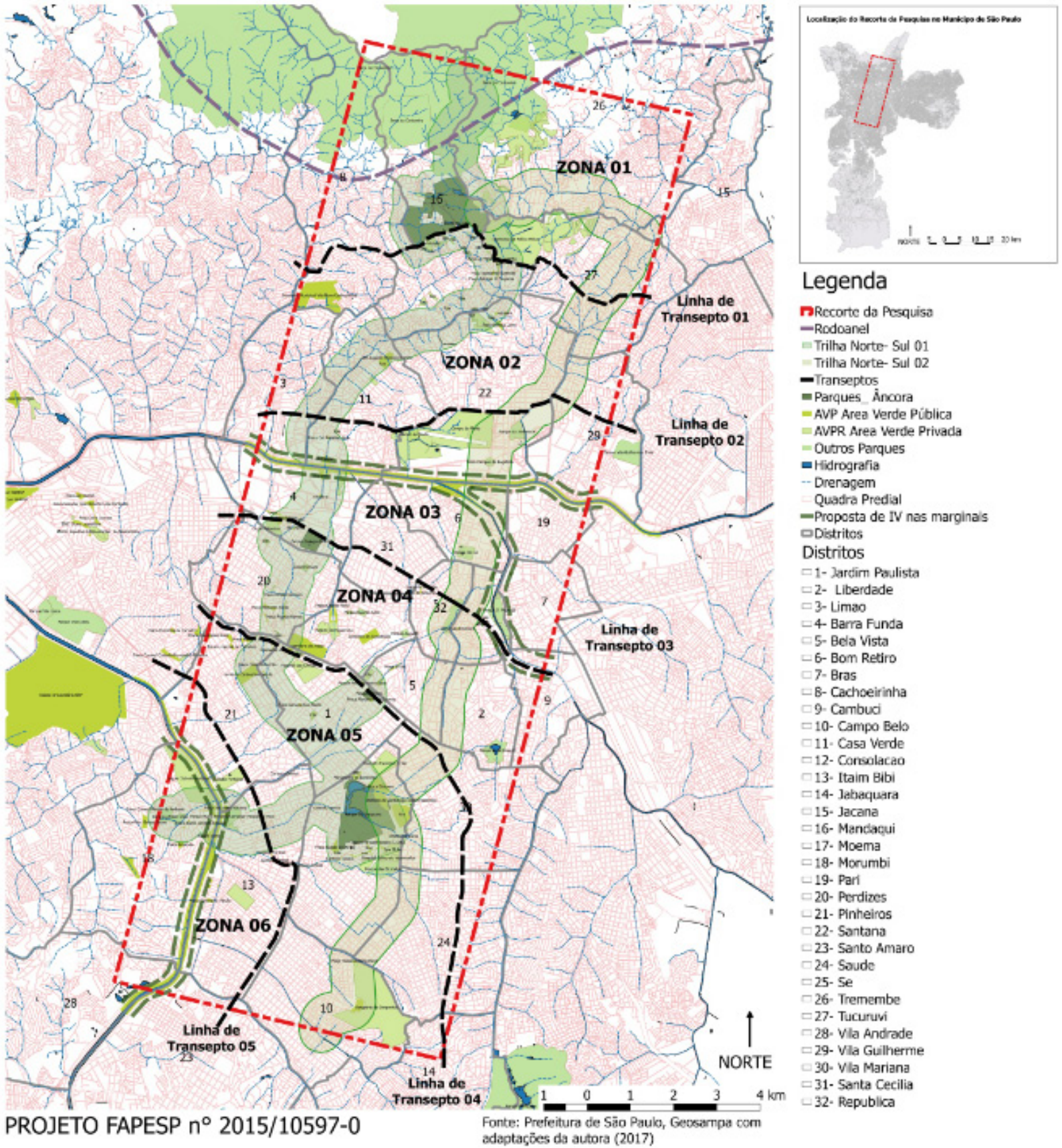

rRecorte da Pesquisa

-Rodoanel

-Trilha Norte- Sul 01

Trilha Norte-Sul 02

- Transeptos

- AVP Area Verde Püblica

AVPR Area Verde Privada

- Outros Parques

- Hidrografia

Drenagem

Proposta de IV nas margina's

-Distritos

Distritos

=1- Jardim Pasulista

-2- Liberdade

3- Limao

-4- Barra Funda

5- Bela Vista

6- Bom Retiro

그-Bras

- B-Cachoeirinha

-9. Combud

- 10-Campo Belo

-11. Casa Verde

-12- Consolacao

-13- Itaim Bibi

-14- Jabaquara

-15- Jacana

=16- Mandacui

- 17. Moema

18- Morumb

-19. Pari

$\square$ 20- Perdizes

21- Pinheiros

$\square 22$ - Santana

23- Santo Amaro

-24- Soude

$-24-50 u$
$-25-5 e$

다. 25 - Tremembe

27- Tucuruvi

28. Vla Andrade

29- Vla Guilherme

30- Vla Mariana

=31- Santa Cecilia

32. Republica

Figura 1 - Mapa da área de estudo: Transectos e Transeptos.

Fonte: Maria de Assunção Ribeiro Franco (Projeto de Pesquisa Auxílio Regular FAPESP de nº 2015/10597-0). 
A Trilha Norte-Sul foi idealizada a partir das hipóteses inspiradas em Benedict e McMahon (2006), sendo: 1. considera que a cidade de São Paulo, devidamente estruturada por uma infraestrutura verde, possa tornar-se resiliente às mudanças climáticas; 2. que os parques devem ser entendidos como áreas núcleo, ligações ou sítios resilientes estratégicos daquela infraestrutura verde, considerando as áreas verdes do entorno dos mesmos como áreas borda, ou 'buffer zones' e como possíveis faixas de compensação ambiental; e, 3. que a arborização urbana intensiva conjugadas à reformulação das calçadas das ruas da cidade é elemento fundamental na amenização das ilhas de calor.

Para os estudos realizados, como mencionado anteriormente, foram criados Cenários Ambientais denominados de "Trilha Norte-Sul 1" (Cenário Ambiental A) e "Trilha Norte-Sul 2" (Cenário Ambiental B).

A "Trilha Norte-Sul 1" (Cenário Ambiental A) consiste num corredor verde experimental, em escala urbana, constituindo uma 'ligação' de infraestrutura verde, cujo eixo segue ao longo de avenidas, ladeado por uma 'buffer zone' (zona de amortecimento) de 500 metros para cada lado do eixo das referidas vias. Este corretor acontece entre o Horto Florestal (e por extensão o Parque Estadual da Cantareira) e o Parque do Ibirapuera (atrelado ao parque do Povo e ao Parque Alfredo Volpi). Esta ligação Norte/Sul da cidade, por meio de um corredor verde, que longe de ser um corredor ecológico constitui-se um "corredor eco-social" de extremo interesse para a cidade de São Paulo².

Já a "Trilha Norte-Sul 2" (Cenário Ambiental B) percorre o retângulo da área de estudo, igualmente de Norte a Sul entre o Horto Florestal e o Ibirapuera, perfazendo um percurso paralelo ao primeiro que interliga outras áreas verdes e/ou permeáveis importantes e emblemáticas da cidade, tais como: a área da Invernada da Polícia Militar, o Parque da Juventude, o Campo de Marte e a Praça Campo de Bagatelle, o Jardim da Luz e a Pinacoteca, o Parque Anhangabaú e a Praça Ramos de Azevedo.

Para o processo de desenvolvimento dos mapas de indicadores morfoclimáticos, foram tratados dados vetoriais urbanos da cidade de São Paulo fornecidos pela Secretaria Municipal de Desenvolvimento Urbano - SMDU. Os dados vetoriais existentes

\footnotetext{
2 A ideia de "corredor eco-social" vem sendo estudada pela Profa. Dra. Maria de Assunção Ribeiro Franco há mais de uma década e foi empregada pela autora como conceito no "Projeto Beira Rio" em Piracicaba no ano de 2002; e, posteriormente, em Franco (2010).
} 
consistem em cadastros realizados em 2008, em formato shapefile (arquivo de forma), com informações do Sistema de Espaços Construídos (edifícios, lotes, quadra predial), Espaços de Integração ou Circulação viária (logradouros, quadra viária); bem como informações sobre Espaços Livres (áreas verdes, áreas não edificadas).

A primeira etapa do processo, consistiu em agrupar os polígonos dos edifícios por altura. Na segunda etapa, os polígonos com a mesma altura e paredes geminadas foram dissolvidos em blocos de edifícios. Essa etapa é necessária para reduzir o volume de informação presente na base de dados e construir blocos de edifícios contínuos, quando estes apresentam mesma altura em um mesmo lote.

Com base no modelo 3D dos sistemas de espaços urbanos para o município de São Paulo, a segunda cartografia desenvolvida caracteriza a altura dos blocos de edifícios presentes nos lotes intersectados pela "Trilha Norte-Sul". Os resultados apontam que dos 89.821 lotes situados na área de estudo, o sistema de espaços edificados, apresenta altura média de 5,74m e máxima de 131,25m (Figura 2 e 3).

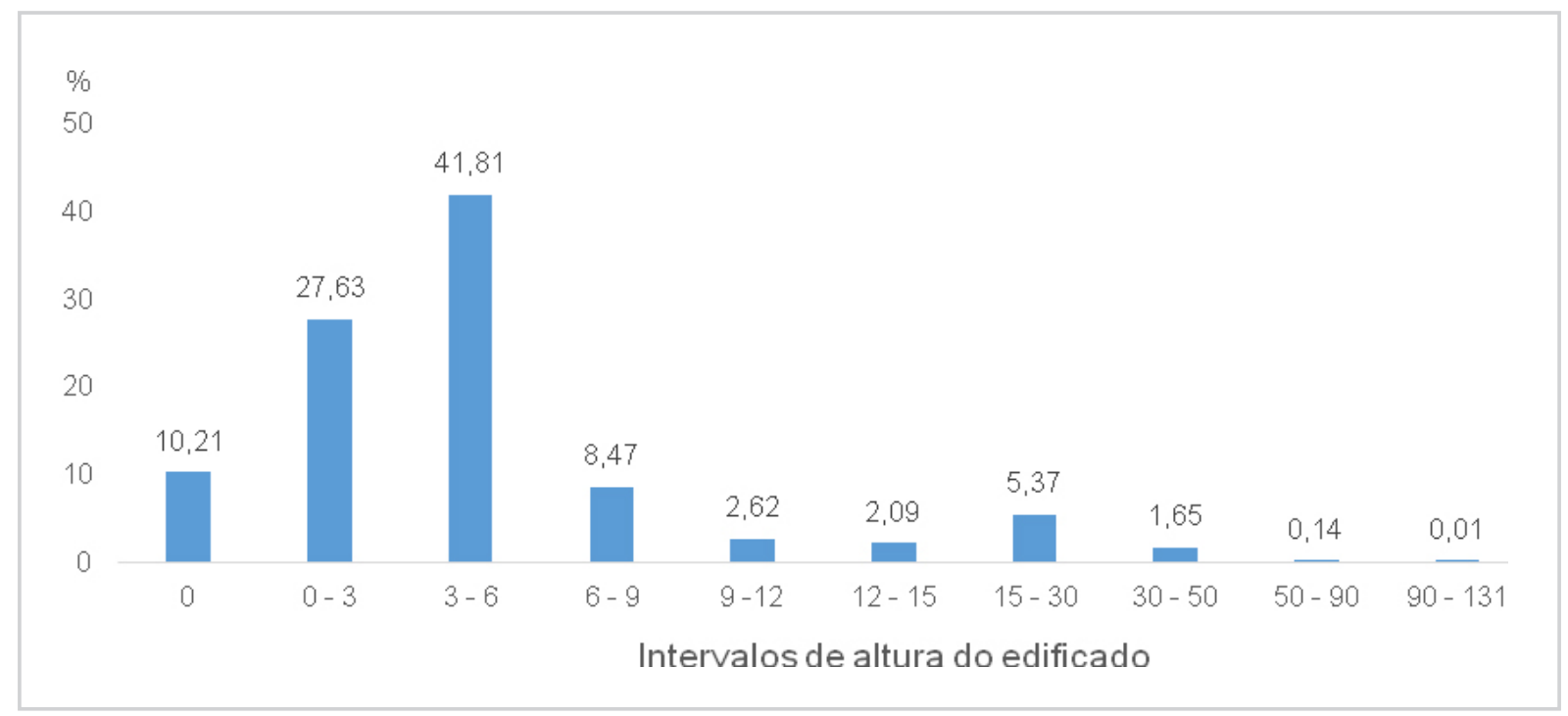

Figura 2 - Altura média dos edifícios por lotes. 


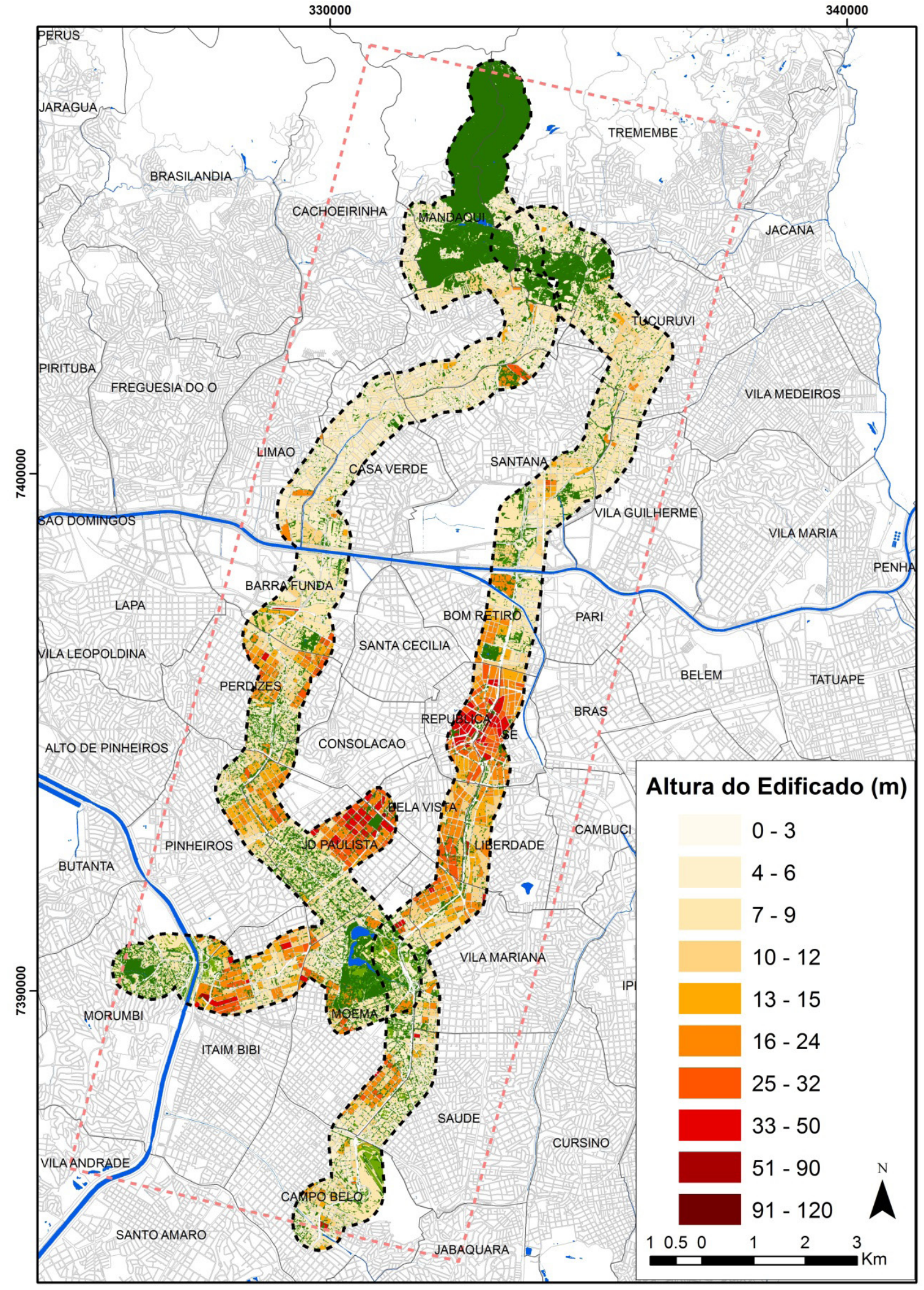

Figura 3 - Mapa da altura média do edificado por lote. 
A terceira cartografia apresenta a densidade de construção dos espaços edificados por lotes. Este indicador corresponde à soma das áreas construídas dividida pela área total do lote (Figura 4).

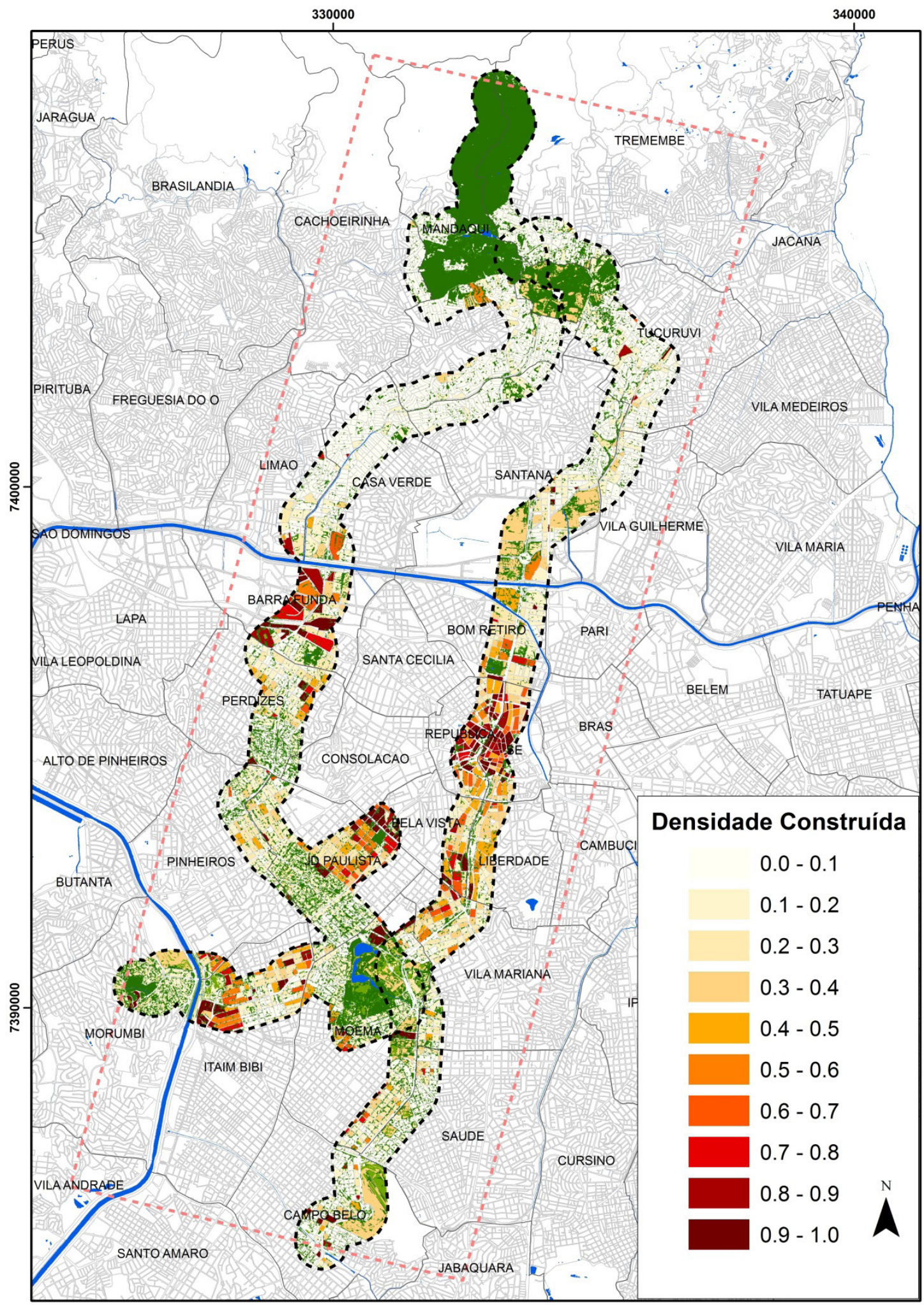

Figura 4 - Mapa da Densidade de Construção por lote da "Trilha Norte-Sul". 
Os resultados foram transformados em um índice que variou de $0-10$, sendo 0 para lotes sem edificação ou com baixa densidade de construção e 10 para os lotes densamente edificados. Os resultados indicam que aproximadamente $95 \%$ do sistema de espaços edificados são classificados com baixa densidade de construção (0 - 2) e menos de $1 \%$ corresponde a elevados níveis de densidade, como pode ser verificado na Figura 5.

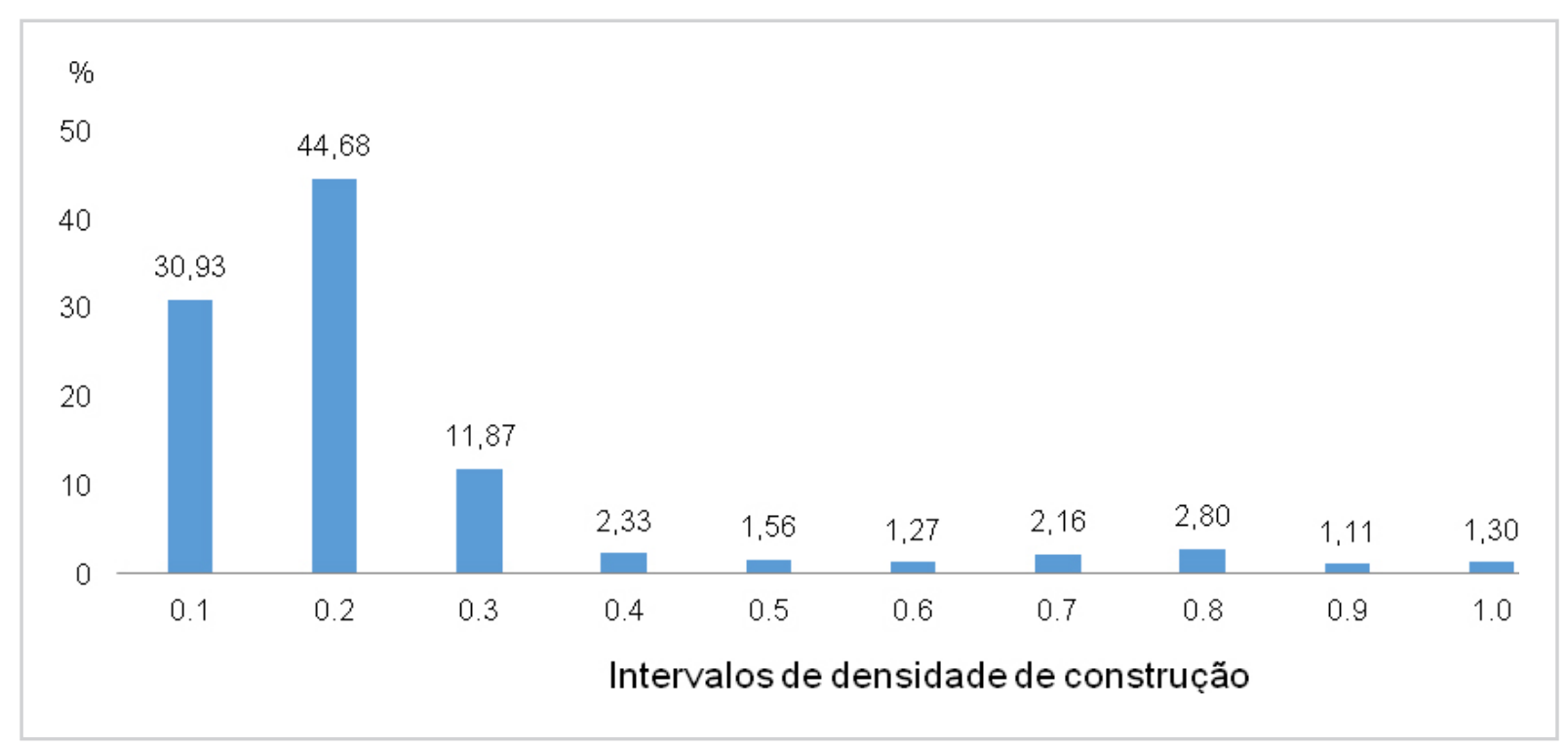

Figura 5 - Densidade de construção do edificado por lotes.

\section{RUGOSIDADE AERODINÂMICA}

Para Oke (1988), o parâmetro superficial crítico que governa a produção de turbulência do fluxo perpendicular em vales urbanos é a rugosidade da superfície. Quanto maior a rugosidade, maior a intensidade da interferência e a influência do atrito.

É um parâmetro chave para o estudo da atmosfera urbana, com oportunidade de identificar potenciais corredores de ventilação. A rugosidade aerodinâmica ainda pode ser utilizada, por exemplo, na modelagem da dispersão de poluentes e em modelos para simulação do perfil dos ventos com o software WasP - Wind Atlas Analysis and Application Program (RATTI et al., 2006).

A rugosidade dos obstáculos presente em superfície está diretamente relacionada com a altura da camada limite inferior da atmosfera urbana (Urban Canopy Layer - UCL). 
Assim, a velocidade e capacidade de escoamento do vento depende da rugosidade presente na superfície (GÀL e UNGER, 2009 ).

Diversos parâmetros (indicadores) podem ser utilizados para descrever a rugosidade aerodinâmica a patir de dados da geometria ou textura da superfície. Os parâmetros de rugosidade descrevem quão eficaz é uma área de superfície na transformação da energia do vento médio, fluindo sobre ela, em movimento turbulento na camada limite acima (DAVENPORT et al., 2000). O comprimento de rugosidade afeta a magnitude de turbulência e quantidades dos fluxos acima da camada limite (GRIMMOND e OKE, 1999).

Para a caracterização da rugosidade aerodinâmica, os parâmetros mais importantes e comumente utilizados são z0 (comprimento da rugosidade) e zd (altura de deslocamento do plano zero) (DAVENPORT et al., 2000; GÁL e UNGER, 2009). Esses parâmetros podem ser estimados com base na medida das fachadas dos edifícios expostos à direção do vento dominante, atuando como barreira à progressão do vento com efeitos na sua velocidade (CORREIA et al., 2015).

Dependendo da direção do vento, a área exposta de fachada dos edifícios pode ser diferente e, por conseguinte, a rugosidade irá ser alterada também. Um mesmo edifício pode atuar como barreira ao vento, com maior intensidade em uma direção ou em outra. Assim, o cálculo do comprimento de rugosidade (z0) e a altura de deslocamento (z) dependem, inicialmente, da análise da direção dos ventos.

Tarifa e Armani (2001), caracterizaram o vento em São Paulo com base nos dados da estação meteorológica do Aeroporto de Congonhas para o período de 1961 a 1990. Segundo os autores, a predominância anual é na direção Sudeste (SE) com 19,6\% e Sul (S) com 16\%, como primeiras predominâncias. Em menor frequência, ocorrem os ventos no vetor Leste (E) com 8,8\%, Noroeste (NO) com 6,3\%, Norte (N) com 5,8\% e Nordeste (NE) com $5,6 \%$. Os menores vetores correspondem aos ventos de Sudoeste (SO) $2,1 \%$, e 1,8\% na direção Oeste (O).

Após a análise do vento dominante para a área de estudo, foram criadas, em ambiente SIG, linhas paralelas distanciadas a cada 20 metros em direção perpendicular (NE - SO), simulando as sessões dos edifícios que atuarão como barreiras ao fluxo do ar, uma vez que se encontram expostas a direção do vento dominante (SE). As linhas ao serem intersectadas com os blocos de edifícios permitem obter o comprimento, altura e área das fachadas. Conforme descrito por Correia et al. (2015), estas métricas são 
necessárias para calcular o Índice de Rugosidade Aerodinâmica. Os resultados da aplicação desta metodologia podem ser visualizados na Figura 6 e 7.

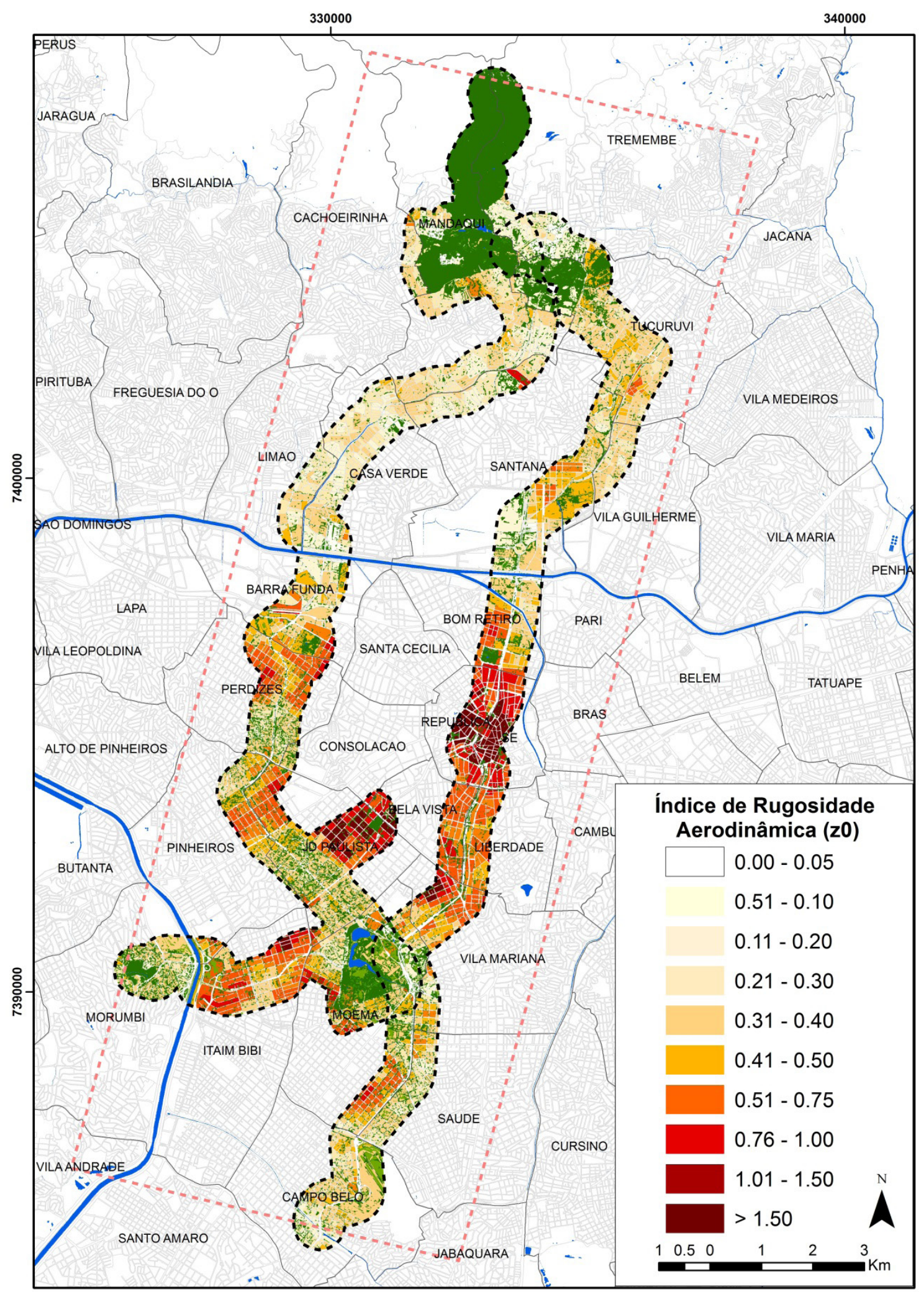

Figura 6 - Mapa da Rugosidade Aerodinâmica por lote para a "Trilha Norte-Sul". 
Quanto maior for este indicador, maior é a altura média do edificado presente no lote. Os maiores valores de rugosidade presente na superfície, estão associados aos maiores segmentos de fachadas dos edifícios, orientados à principal direção do vento para São Paulo (SE). Observa-se que, a rugosidade aerodinâmica apresenta uma média de valores inferiores a 0.5 , perfazendo aproximadamente $70 \%$ da área de estudo. Os valores de elevada rugosidade aerodinâmica, compreendidos entre $1.0(4,52 \%)$ e 1.5 $(2,52)$, correspondentes as áreas mais adensadas verticalmente e horizontalmente, podem ser verificados principalmente nas áreas situadas próximo as subprefeituras Bela Vista, Consolação, Jardim Paulista, Itaim Bibi, Sé e República.

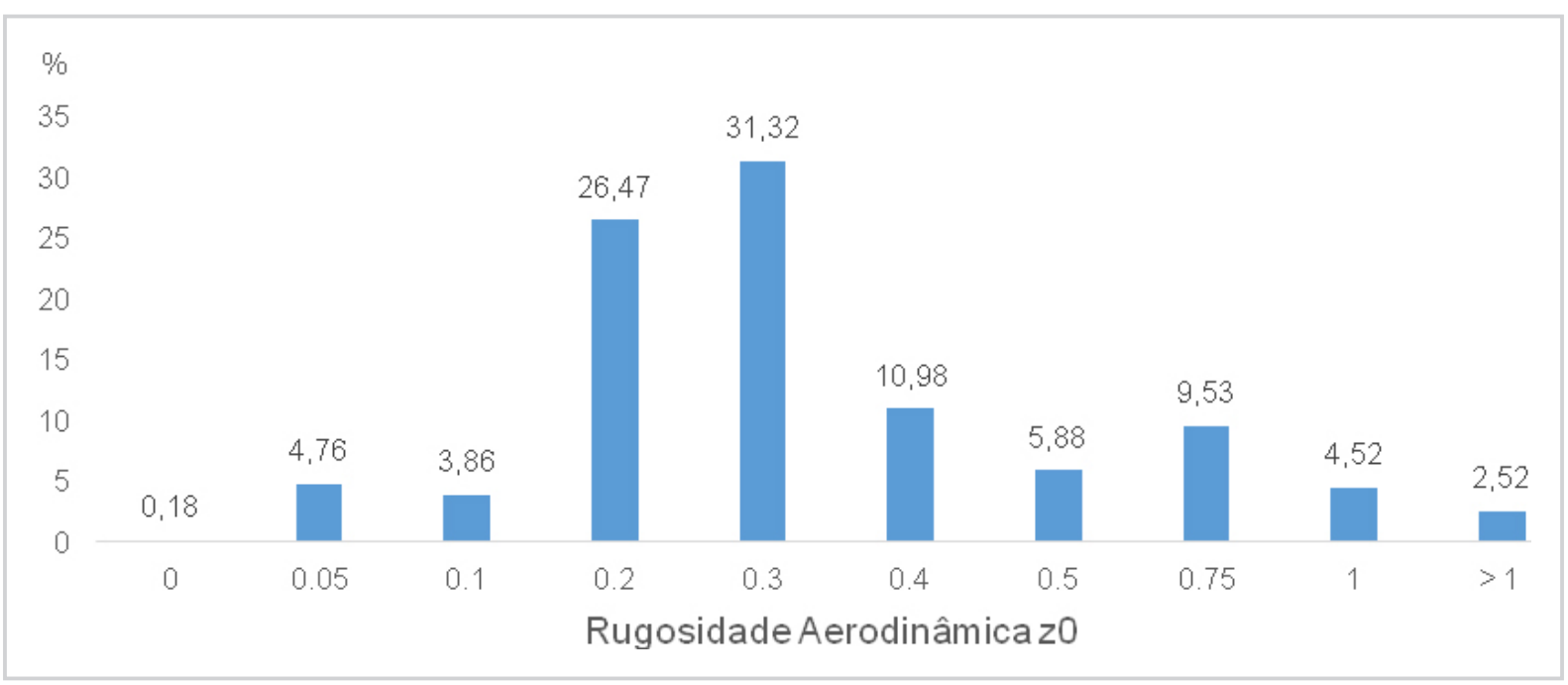

Figura 7 - Índice de rugosidade aerodinâmica - z0.

\section{FATOR H/W}

A relação entre a altura média do edificado, presente no sistema de espaços contruídos, em razão com a distância que separam os edifícios no sistema de espaços de cirulação viária e espaços livres, pode ser representada pelo Fator H/W. Este indicador apresenta relação direta com a fração de céu visível (Sky View Factor), constituindo um dos principais indicadores utilizados em análises climáticas urbanas para estimar e caracterizar a intensidade do efeito da ICU (OKE, 1987; Alcoforado et al., 2005).

O Fator H/W, possibilita caracterizar o nível de obstrução do conjunto edificado em relação ao céu e ao sol, e avalia a influência da morfologia urbana em termos da radiação solar recebida (MARTINS et al., 2013). Quanto mais obstruído for um local, 
maior o Fator $\mathrm{H} / \mathrm{W}$ e, então, maior será a dificuldade do tecido urbano dispersar para a atmosfera a carga térmica armazenada em sua estrutura durante o dia.

Este indicador permite, ainda, auxiliar no estudo do balanço radiativo dos espaços urbanos, inferindo em termos térmicos na quantidade e disponibilidade de luz natural. Para a ventilação urbana, este indicador caracteriza a obstrução ou disponibilidade de espaço junto a superfície disponível para o fluxo de ar dispersar poluentes e calor.

O Fator H/W (OKE, 1987) foi estimado, para a área de estudo, com base na razão da altura dos edifícios pela largura dos espaços que os separam conforme descrito por Correia et al. (2015). Este índice determina o impacto da obstrução dos edifícios em relação ao seu entorno, indicando as áreas com menor fração de céu visível, como ilustram as Figuras 8 e 9.

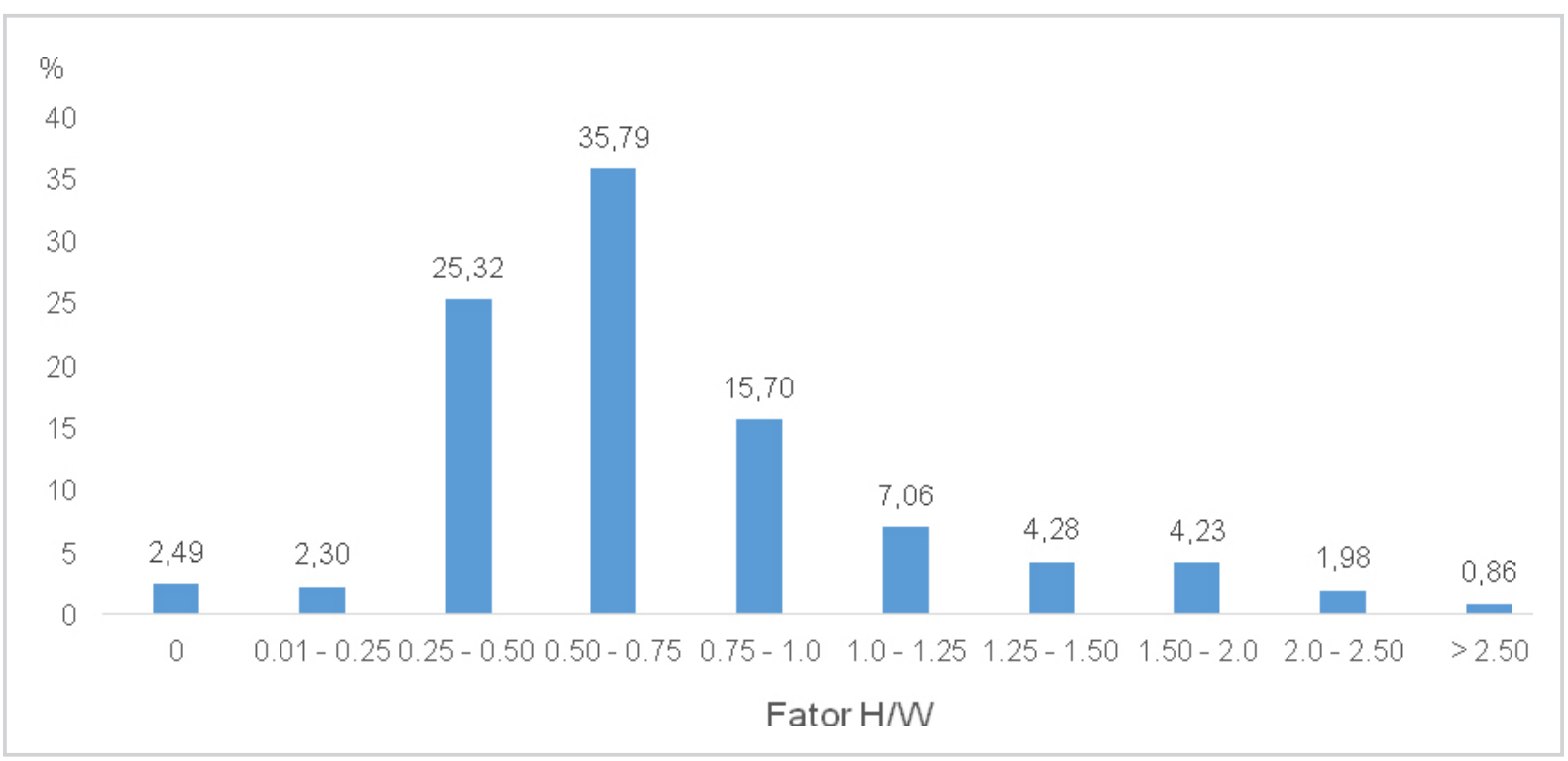

Figura 8 - Resultados do Fator H/W.

Os resultados apresentam, em sua maioria, valores inferiores a 0.75 correspondendo à aproximadamente $65 \%$ da área de estudo, indicando áreas em que a altura média do edificado por lote não é superior aos espaços abertos circundantes. 


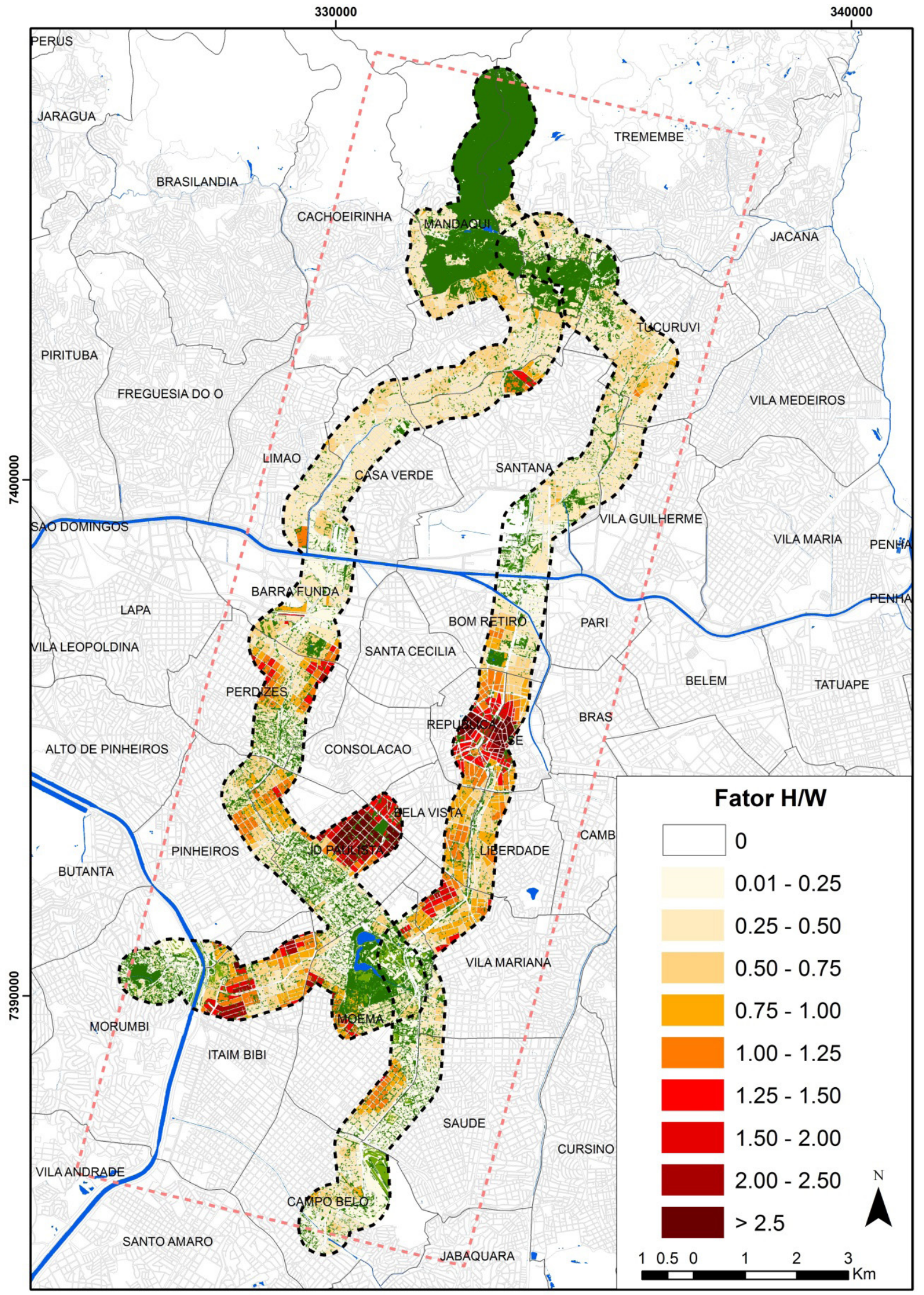

Figura 9 - Fator H/W, dado pela razão da altura dos edifícios pela largura dos espaços que os separam. 
Nas áreas em que a altura média do edificado por lote é maior que a distância dos espaços que os separam (superior a 2.0), o Fator H/W apresenta os valores superiores para menos de $3 \%$ dos espaços presentes na "Trilha Norte-Sul". Essas regiões apresentam no sistema de espaços de circulação viária e espaços livres, menores condições de insolação e maior aptidão a concentração de poluentes. Os maiores valores do Fator $\mathrm{H} / \mathrm{W}$, podem ser verificados principalmente nas áreas situadas próximo as subprefeituras Bela Vista, Consolação, Jardim Paulista, Itaim Bibi, Sé e República.

\section{POROSIDADE}

A porosidade urbana pode ser interpretada como a razão que quantifica o volume de ar livre sobre a camada de cobertura do sistema de espaços construídos - volume da UCL. A porosidade está relacionada com o quão penetrável é uma área para a circulação do fluxo de ar. Gàl et al. (2015), refere-se a porosidade urbana como a relação entre as partes penetráveis e impenetráveis de uma camada de ar sobre uma determinada área. A porosidade caracteriza o efeito global do tecido urbano no incremento ou na redução da velocidade média do vento, respectivamente, responsáveis por alterar significativamente a forma de deslocamento das massas de ar.

De acordo com estas definições, segundo Correia el al. (2015), para a avaliação da porosidade urbana é necessário, como parâmetro de entrada, estimar o volume dos elementos presentes no sistema de espaços construídos. Ou seja, o volume de ar que é ocupado por edifícios em relação altura limite da UCL e independente da orientação do edificado. Essas medidas foram elaboradas considerando a altura média dos edifícios presentes nos lotes, multiplicados pela área do edificado.

Para além do volume do edificado são necessárias informações referentes às áreas de lote e a altura de toda a UCL, que foi definida como constante para definir o volume de ar livre. Este valor constante é definido com base no levantamento da altura máxima do edificado presente na camada limite inferior para a área de estudo. Os resultados do índice de Porosidade Urbana, podem ser verificados nas Figuras 10 e 11. 


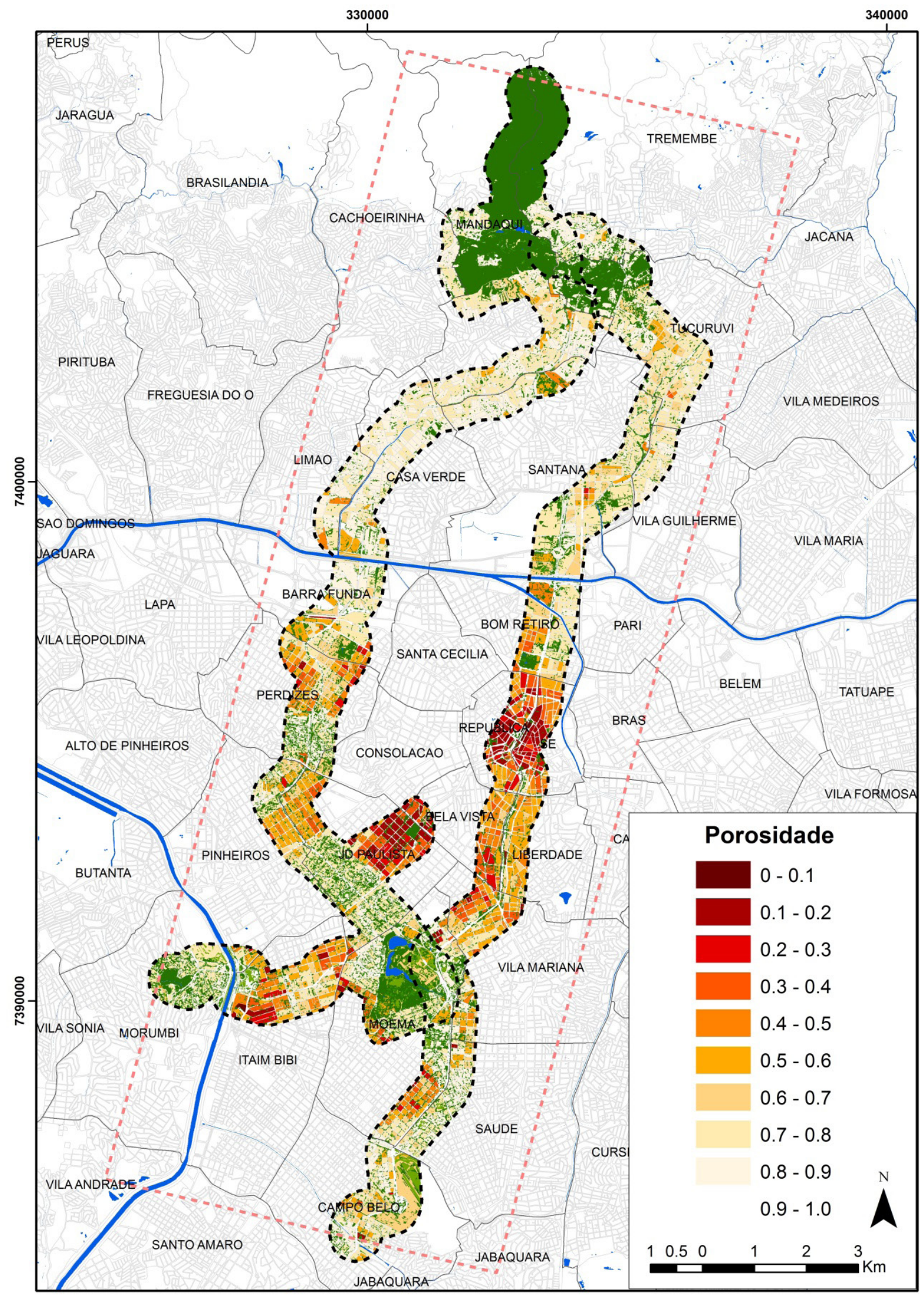

Figura 10 - Mapa da Porosidade do tecido urbano. 
A porosidade urbana na "Trilha Norte-Sul", apresenta as maiores porcentagens nas classes com intervalos superiores a $0.8(68 \%)$, ou seja, compreende uma elevada proporção do sistema de espaços edificados definida por baixa volumetria, refletindo boas condições para a circulação do ar.

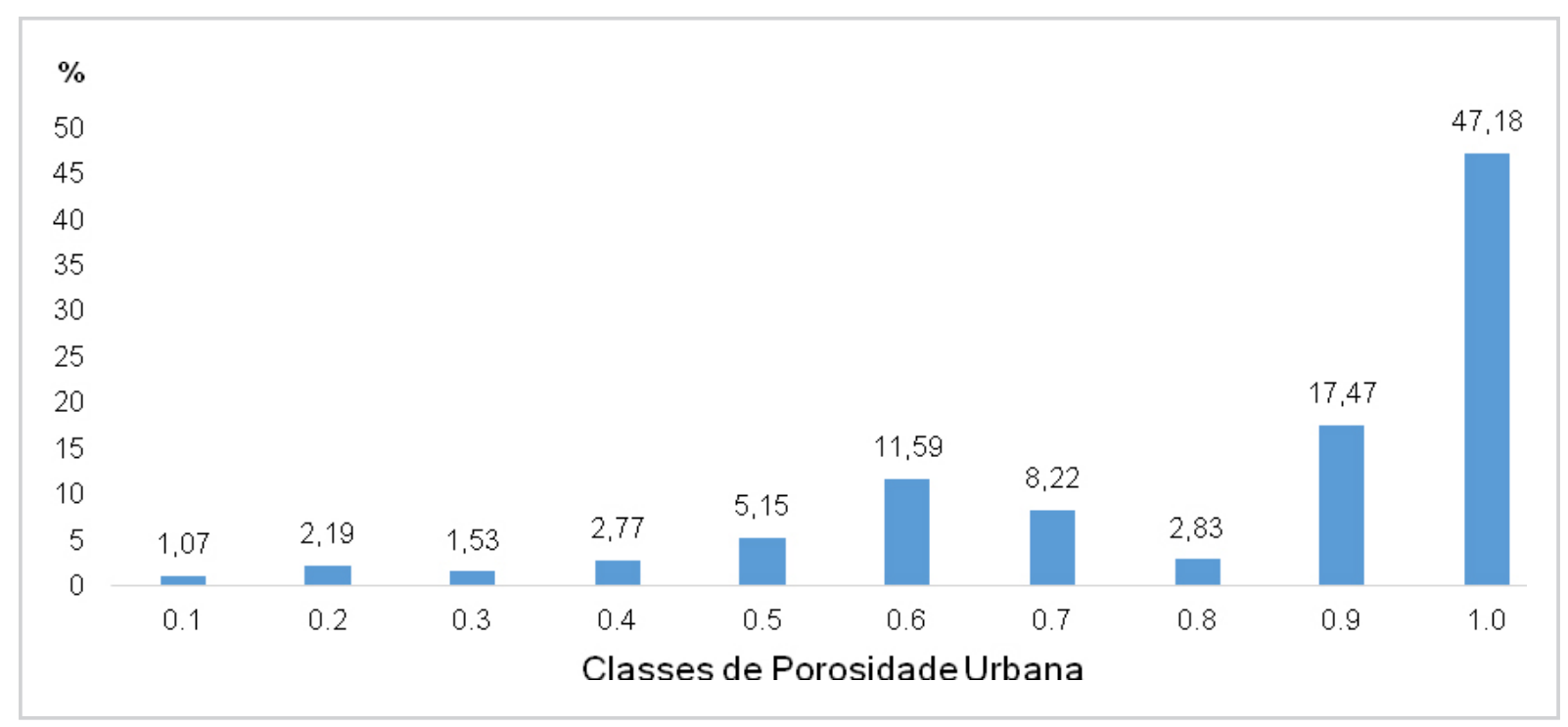

Figura 11 - Resultados do índice de Porosidade Urbana.

Os menores índices de porosidade urbana, quando somados, representam valores inferiores a $5 \%$, destacando as áreas situadas junto às subprefeituras da Sé e República. Nestas áreas, por vezes, os lotes de edificados apresentam intensa densidade de ocupação e, em alguns casos, a inexistência de espaços livres. Já nas regiões intersectadas pelas principais avenidas de comércio, em que há elevada verticalização, os resultados apontam para um elevado volume do edificado.

\section{CORREDORES DE VENTILAÇÃO}

Os corredores de ventilação podem desempenhar um importante papel na redução da poluição do ar na parte interna das áreas urbanas. Conforme ressalta Alcoforado et al. (2005), o vento predominante em uma localidade possui a capacidade de "limpar" a cidade. A obstrução dos corredores de ventilação natural, implica no aumento dos picos de poluição e consequências na saúde da população. $O$ aumento da poluição pode ser ainda associado a um incremento na intensidade da ICU e desconforto térmico. 
O sistema de espaços de integração viária e o sistema de espaços livres de construção, apresentam alta probabilidade de escoamento do vento e um alto grau de conectividade. Essas caratcterísiticas permitem que ventilação em ambientes urbanos oriente-se por caminhos com menor número de obstáculos, ou seja, espaços com menor resistência ao escoamento.

Diversos estudos de caracterização da morfologia urbana, para fins climáticos, mostram as potencialidades do uso da informação para determinação de corredores de ventilação (GÀL e UNGER, 2009; WONG et al., 2010). Para caracterização dos corredores de ventilação, Matzarakis e Mayer (1992), resumiram os requisitos necessários considerando os seguintes pontos:

(A) z0 inferior a 0,5 m;

(B) zd deve ser inferior a $3 \mathrm{~m}$;

(C) comprimento do corredor suficientemente grande numa direção, pelo menos $1 \mathrm{~km}$;

(D) largura do corredor suficientemente grande (relação com a altura do obstáculo), mas não inferior a $50 \mathrm{~m}$;

(E) as bordas dos corredores de ventilação devem ser lisas;

(F) a largura dos obstáculos num percurso não deve ser superior a $10 \%$ da largura do percurso;

(G) a altura do obstáculo num percurso não deve ser superior a $10 \mathrm{~m}$;

(H) os obstáculos dentro de um percurso devem ser orientados de modo que sua maior largura seja paralela ao eixo do percurso;

(I) os únicos obstáculos dentro de um percurso devem ter uma razão de altura para a distância horizontal, entre dois obstáculos sucessivos, de 0,1 para edifícios e 0,2 para árvores.

A última cartografia deste estudo espacializa os possíveis corredores de ventilação presentes na área de estudo. O mapa resultante foi desenvolvido com base na morfologia urbana ( $z 0<0.5, z d<3 \mathrm{~m}, W>50$ e $1 \mathrm{~km}$ de extensão), e na metodologia descrita por Matzarakis e Mayer (1992). 
A área de estudo apresenta propensão a ter $8.30 \%$ da área total limite e $12.62 \%$ dos espaços não edificados, como possíveis áreas com condições para serem corredores de ventilação (Figura 12 e 13).

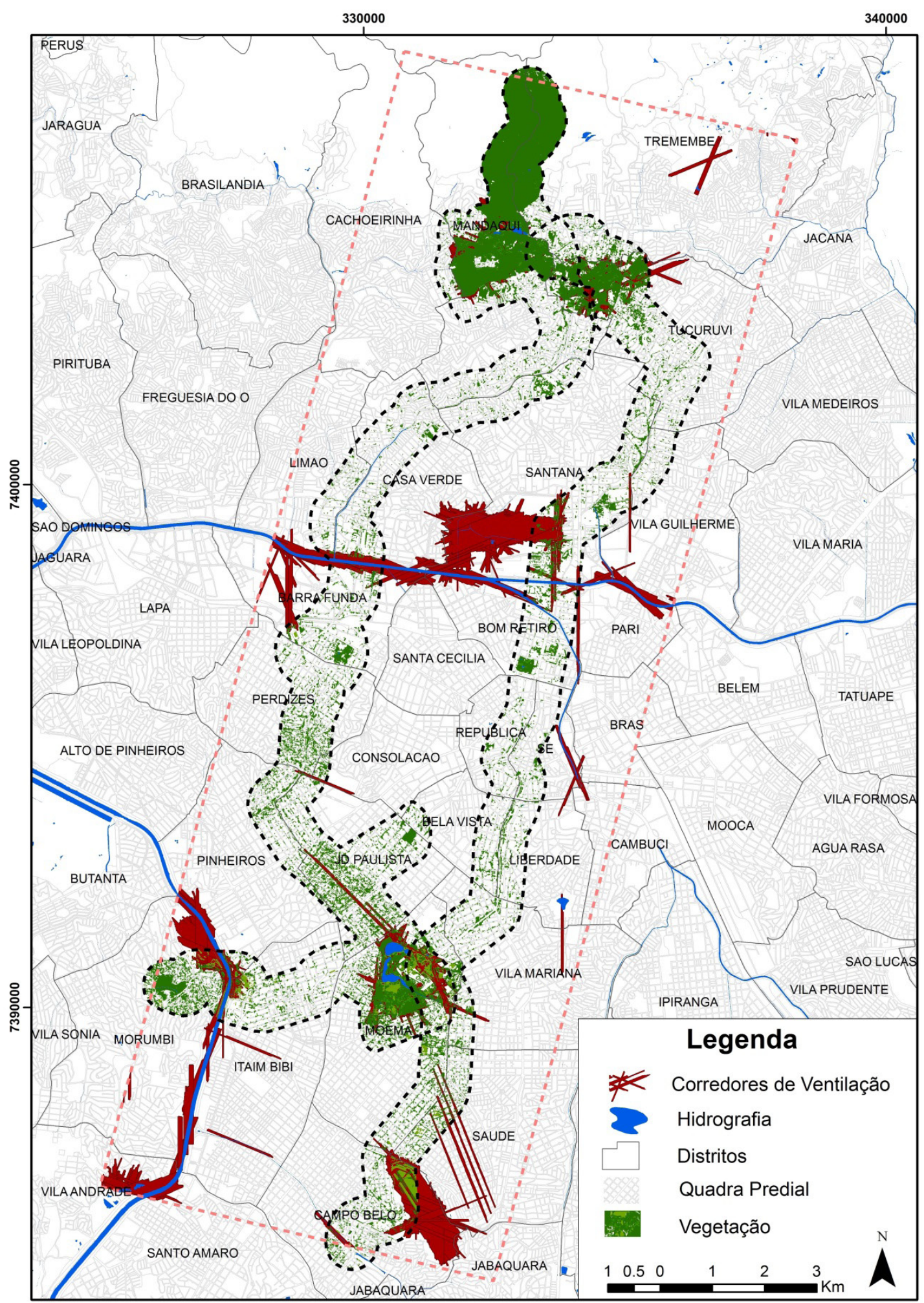

Figura 12 - Corredores de ventilação na área de estudo. 
É possível verificar uma maior disponibilidade de corredores de ventilação, orientados para as direções: ESE - ONO (20,70\%), SE - NO (20,20\%), E - O (16,93\%) e SSE - NNO (15,85\%). Os valores intermediários estão representados pelos vetores em direção N - S $(9,12 \%)$ e NNE - SSO $(8,50 \%)$ e os menores valores para as direções de vento ENE- OSO $(6,40 \%)$ e NE - SO $(2,30 \%)$.

A distribuição espacial dos espaços, com boas condições de serem corredores de ventilação, mostra correlação com a predominante dos ventos em São Paulo. As maiores áreas disponíveis para os corredores de ventilação estão orientados nas direções ESE - ONO e SE - NO, inseridas no vetor de direção do vento predominante da cidade (SE).

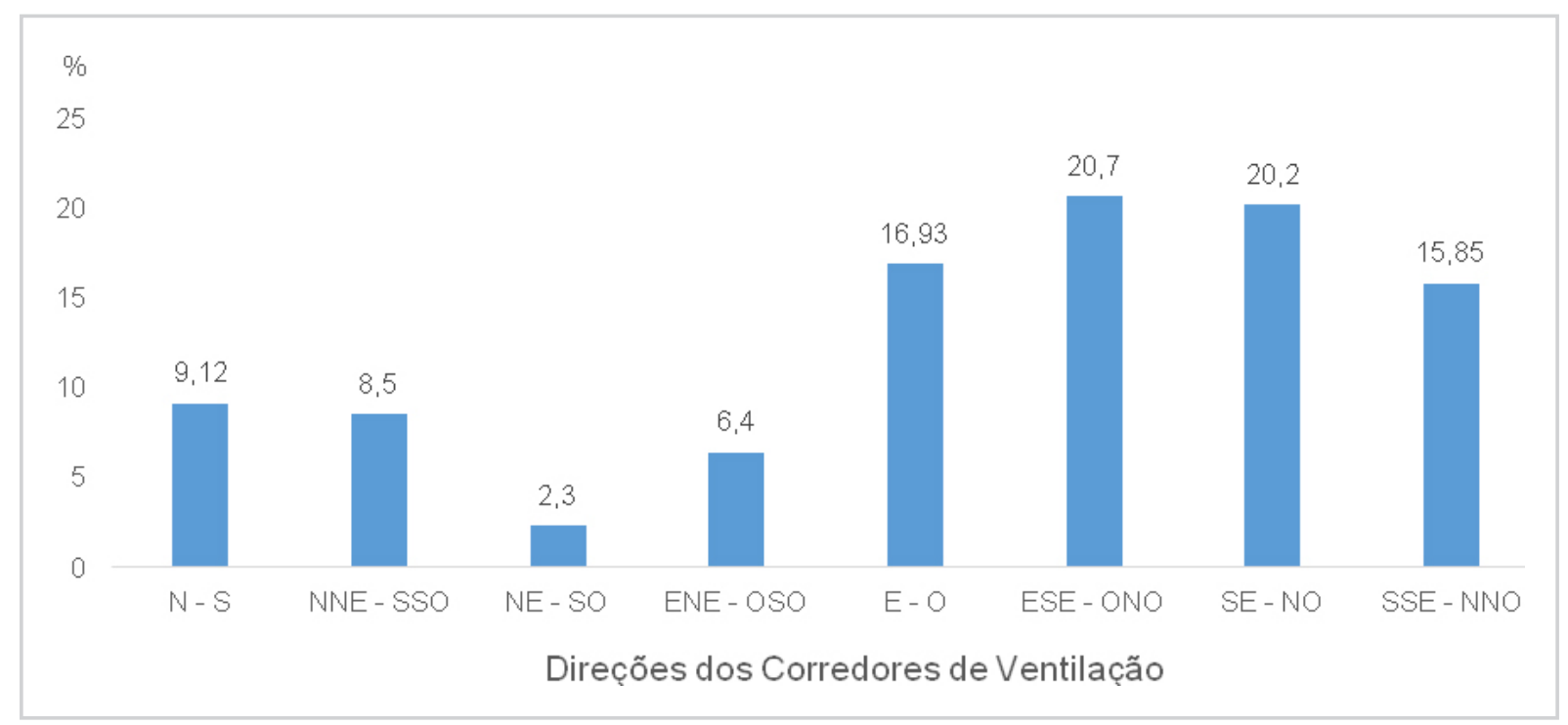

Figura 13 - Gráfico dos corredores de ventilação por direção do vento.

Destacam-se, ainda, como áreas com boas condições para corredores de ventilação, os espaços intersectados pelos ventos na direção $N-S$ e $E-O$. Estes últimos apresentam como característica principal as áreas ocupadas pelo Rio Tietê e, parcialmente também, parte do Rio Pinheiros (parte sul). Apesar dos ventos de E - O corresponderem a menos de $11 \%$ dos ventos, o bom potencial de ventilação nesses espaços pode ajudar na dispersão de poluentes concentrados ao longo das principais vias. Representa, também, uma oportunidade de conectar a circulação entre o vento das áreas mais frescas para o centro. 


\section{CONCLUSÕES}

A caracterização morfológica para fins climáticos da "Trilha Norte-Sul", com base nos elementos presentes no sistema de espaços urbanos, possibilitou a análise e distribuição espacial dos índices de rugosidade aerodinâmica (z0), Fator H/W e porosidade urbana. Estes indicadores foram fundamentais para a delimitação de possíveis corredores de ventilação na área de estudo.

A manutenção de corredores de ventilação em áreas urbanas desempenha um papel fundamental no desenvolvimento da circulação do ar, com reflexos na distribuição espacial e intensidade da ICU, além de atuar na dispersão da poluição do ar na parte interna da cidade.

É possível estabelecer, com base nos resultados apresentados, as áreas em que o planejamento urbano deve considerar manter baixo os níveis de rugosidade do tecido urbano. Estes níveis podem ser mantidos, no sistema de espaços edificados, tendo como base a inserção da cobertura vegetal ao longo de corredores de ventilação que estão orientados na direção do vento dominante em São Paulo. Estas medidas poderiam maximizar os reconhecidos benefícios da vegetação em ambiente urbano e, também, permitir a maior eficiência da atuação do vento, dois elementos fundamentais na dispersão de calor e no conforto bioclimático.

Observou-se que o comportamento da morfologia urbana em relação à direção dos ventos predominantes (SE e S), apresenta reflexos no campo térmico urbano da área de estudo. As possíveis regiões a serem mais afetadas pelo sobreaquecimento das superfícies, considerando a análise das propriedades aerodinâmicas, apontam para as subprefeituras (Bela Vista, Consolação, Jardim Paulista, Sé e República), pois estas não apresentam critérios morfológicos para a caracterização de possíveis corredores de ventilação.

No entanto, os resultados da caracterização morfológica devem ser analisados com cautela, considerando a complexidade das diferentes áreas que a "Trilha Norte-Sul" atravessa no tecido urbano da cidade de São Paulo e a complexidade da análise do vento em ambientes urbanos. Cada sistema de espaço urbano apresenta resposta diferente na capacidade de atuar como barreira à progressão do vento.

Estudos futuros para o modelo apresentado podem incluir a análise dos tipos de superfície, uma vez que, os ventos que atravessam superfícies cobertas por vegetação 
arbórea com elevada porosidade, têm uma capacidade de arrefecimento superior à aqueles que atravessam superfícies impermeáveis.

Simulações computacionais para verificação dos efeitos na velocidade e direção do vento, a partir de agora, poderiam ser desenvolvidas tendo como base a cartografia de rugosidade aerodinâmica apresentada e o modelo de topografia.

\section{REFERÊNCIAS BIBLIOGRÁFICAS}

ALCOFORADO, M. J.; ANDRADE, H., LOPES, A.; VASCONCELOS, J.; VIEIRA, R. Orientações climáticas para o ordenamento em Lisboa. Área de Investigação de Geo-Ecologia, Relatório n. ${ }^{\circ}$ 4, Centro de Estudos Geográficos, Lisboa, 81 p, 2005.

ANDRADE, H. O clima urbano - natureza, escalas de análise e aplicabilidade. Finisterra - Revista Portuguesa de Geografia, Lisboa. XL (80): p. 67-91, 2005.

BENEDICT, Marc A.; MCMAHON, Edward T. Green Infrastructure: Linking Landscapes and Communities, Washington, Island Press, 2006.

CAVALHEIRO, F.; DEL PICCHIA, P. C. D. Áreas Verdes: conceitos, objetos e diretrizes para o planejamento. Vitória/ES, Anais I e II... Congresso Brasileiro Sobre Arborização Urbana. p. 29-35, 1992.

CORREIA, E.; LOPES, A.; MARQUES, D. An automatic GIS procedure to calculate urban densities to use in Urban Climatic Maps. In: 9th International Conference on Urban Climate 12th Symposium on the Urban Environment, Tolouse - France, 2015.

DAVENPORT, A. G.; GRIMMOND, C. S. B.; OKE, T. R.; WIERINGA, J. Estimating the roughness of cities and sheltered country. In: Proceedings of the 12th conference on applied climatology. Boston: American Meteorological Society. p. 96-9, 2000.

FARIA, J. R. G. Caracterização do vento na camada intra-urbana da cidade de BauruSP. Anais do XI Congresso Brasileiro de Meteorologia, Rio de Janeiro. SBMet. p. 3967-3976, 2000.

FARIÑA, T. J. La ciudad y el medio natural. Madrid: Akal, 1998. 
FRANCO, M. A. R. Infraestrutura Verde em São Paulo: o caso do Corredor Verde Ibirapuera-Villa Lobos. Revista LabVerde, Departamento de Projeto - FAUUSP, n.1, 2010, http://dx.doi.org/10.11606/issn.2179-2275.v0i1p135-154.

GÁL, T.; UNGER, J. Detection of ventilation paths using high-resolution roughness parameter mapping in a large urban area. Building and Environment. p.198-206, 2009.

GRIMMOND, C.; OKE, T. R. Heat storage in urban areas, local-scale observations and evaluation of a simple model. Applied Meteorology. v. 38, p. 922-940, 1999.

GROMKE, C. RUCK, B. Pollutant concentrations in street canyons of different aspect ratio with avenues of trees for various wind directions. Bound. Layer Meteorol. 144, p. 41-64, 2012.

LOMBARDO, M. A.; SILVA FILHO, D.; FRUEHAUF. A. L.; PAVAN, D. C. O Uso de Geotecnologias na Análise da Ilha de Calor, Índice de Vegetação e Uso da Terra. Revista Geonorte. v.1, p. 520-529, 2012.

LOPES, A. Modificações no Clima de Lisboa como consequência do crescimento urbano, vento, ilha de Calor de superfície e balanço energético. Dissertação de Doutoramento em Geografia Física. Lisboa. 375p, 2003.

LOPES, A. Sobreaquecimento das cidades. Causas e medidas para a mitigação da ilha de calor de Lisboa. Territorium. p.15: 39-52, 2009.

LOPES, A.; LOPES, S.; MATZARAKIS, A.; ALCOFORADO, M. J. The influence of the summer sea breeze on thermal comfort in Funchal (Madeira). A contribution to tourism and urban planning. Meteorologische Zeitschrift. p. 553-564, 2011.

MARTINS, T. A. de L.; BONHOMME, M.; ADOLPHE, L. Análise do impacto da morfologia urbana na demanda estimada de energia das edificações: um estudo de caso na cidade de Maceió, AL. Ambiente Construído, Porto Alegre. v. 13, n. 4, p. 213-233, 2013.

MATZARAKIS, A.; MAYER, H. Mapping of urban air paths for planning in Munchen. Wiss Ber Inst. Meteorol. Klimaforsch. Univ. Karlsruhe. p. 16, 13-22, 1992. 
NG, W. Y.; CHAU, C. K. Evaluating the role of vegetation on the ventilation performance in isolated deep street canyons. Int. J. Environ. Pollut. p. 50, 98-110, 2012.

OKE, T. R. Boundary layer climates. Routledge, London. 1987.

OKE, T. R. The urban energy balance. Progress in Physical Geography. p. 471-508, 1988.

OKE, T. R. The heat island of the urban boundary layer: characteristics, causes and effects. Wind Climate in Cities. p. 81-107, 1995.

PARLOW, E. Net radiation of urban areas. Future trends in remote sensing. MCR Lab. Balkema Roterdã. p. 221-226, 1998.

PRATA SHIMOMURA, A. R.; FROTA, BARROS, A.; CELANI, G. Modelos Físicos na Análise de Ventilação Urbana: o uso de Túnel de Vento. Fórum Patrimônio : Ambiente Construído e Patrimônio Sustentável (UFMG. Online), v. 3, p. 2, 2009.

PRATA SHIMOMURA, A. R.; LOPES, A. S. ; CORREIA, E. . Urban Climatic Map Studies in Brazil: Campinas. In: Edward Ng; Chao Ren. (Org.). The Urban Climatic Map: A Methodology for Sustainable Urban Planning. New York, NY: Taylor \& Francis Group. v.1, p. 1-528, 2015.

RATTI, C.; DI SABATINO, S.; BITTER, R. Urban texture analysis with image processing techniques: wind and dispersion. Theor. and Appl. Climatol. p. 84, 77-99, 2006.

SALAT, S. Les et les formes. Sur L'urbanisme durable. 1. ed. Paris: CSTB, v. 1, 2011.

SÃO PAULO (Município), Secretaria Municipal de Planejamento Urbano /Secretaria Municipal do Verde e Meio Ambiente. Atlas. MDC - Mapa Digital da Cidade de São Paulo. Disponível em: <http://downloadfolhasscm.prefeitura.sp.gov.br>. Acesso em 10, dez. 2016.

SÃO PAULO (Município), Secretaria Municipal de Planejamento Urbano /Secretaria Municipal do Verde e Meio Ambiente. Atlas Ambiental do Município de São Paulo. São Paulo, 2002. 
SCHERER, D.; FEHRENBACH, K.; BEHA, H. D.; PARLOW, E. Improved concepts and methods in analysis and evaluation of the urban climate for optimizing urban planning processes. Atmospheric Environment, p. 33: 4185-4193, 1999.

TARIFA, J. R.; AZEVEDO, T.R. (Org.). Os climas na cidade de São Paulo: teoria e prática. São Paulo: Pró-Reitoria de Cultura e Extensão. Universidade de São Paulo: Laboratório de Climatologia. Faculdade de Filosofia, Letras e Ciências Humanas, Universidade de São Paulo, São Paulo, 199p, 2001.

VOS, P. E.; MAIHEU, B.; VANKERKOM, J.; JANSSEN, S. Improving local air quality in cities: to tree or not to tree? Environ. Pollut. p. 183, 113-122, 2013.

WONG, M. S.; NICHOL, J. E.; TO, P.H.; WANG, J. A simple method for designation of urban ventilation corridors and its application to urban heat island analysis. Building and Environment. p. 45(8), 1880-1889, 2010. doi:10.1016/j.buildenv.2010.02.019. 